\title{
Characteristics of high waves observed at multiple stations along the east coast of Korea
}

\author{
S.-H. Oh and W.-M. Jeong \\ Coastal Development \& Ocean Energy Research Department, Korea Institute of Ocean Science and Technology, Ansan \\ 426-744 Republic of Korea
}

Correspondence to: S.-H. Oh (ohsangho@kiost.ac)

Received: 13 May 2013 - Published in Nat. Hazards Earth Syst. Sci. Discuss.: 16 July 2013

Revised: 28 October 2013 - Accepted: 25 November 2013 - Published: 23 December 2013

\begin{abstract}
In recent several years, extremely high waves occasionally struck the Korean coast of the East Sea and caused severe coastal disasters almost every winter season. In this paper, characteristics of such high waves are reported by analyzing wave records collected at multiple stations along the east coast of Korea. Meteorological data obtained at relevant weather stations were also used in the analysis. The reason for appearance of the high waves was identified as the strong northeasters due to extra-tropical low pressure systems that had been rapidly developing in the East Sea. The general mechanism concerning the formation and spatial evolution of such strong low pressure systems was more clearly understood through the synthetic analysis of the wave and meteorological data. In particular, the influence of spatiotemporal features of the low pressure system on the resulting characteristics of the high waves was described in more detail in this study. Since the overall wave direction was also northeast, the first wave arrival time on the coastline became later for a wave station whose latitude is lower. At present, however, the arrival time of such high waves on the coast as well as their intrinsic characteristics such as wave height and period are not satisfactorily predicted by the daily weather forecast. Hence, it is necessary to enhance predictability of the high waves by investigating developmental mechanisms of the strong low pressure system in the winter season more thoroughly.
\end{abstract}

\section{Introduction}

During the past several years, the east coast of Korea has experienced exceptionally high storm waves several times in the winter season. To mention a few examples, the significant wave height reached its maximum of $9.69 \mathrm{~m}$ near Sokcho harbor on 21 October 2006, which was the maximum wave height ever observed on the east coast of Korea (Jeong et al., 2007). More recently, on the first day of 2011, unusually high waves of $H_{\mathrm{s}}=6.71 \mathrm{~m}$ struck Jukbyeon port. Besides these records, the occurrence of winter storm waves higher than $3 \mathrm{~m}$ once or more times every year has become common in recent years. These storm waves caused severe casualties, damage to coastal structures, and extensive beach erosion along the east coast of the Korean Peninsula, which had rarely occurred until very recently. Although it is not clearly certain whether higher waves are more frequently coming to the coastal waters as a result of possible effects of climate change (e.g., Vanem et al., 2012), due to the lack of any long-term data of continuously monitoring waves around this area, some long-lived local citizens testify that such unusually high waves scarcely appeared in the past. Indeed, the scale of the human death toll and property damage attributed to the high waves has maintained an increasing trend during the recent decades.

In particular, the repeated loss of human lives due to the occurrence of huge waves has gradually been becoming public concern. Almost every year, human casualties are occurring due to suddenly appearing large waves near the beaches, coastal roads, or the navigating ships. In particular, most of the casualties on coastal zones occurred under mild rather than wild weather conditions so that people were unlikely to be wary of the risk of sudden wave occurrence. Meanwhile, similar appearances of the abnormally high waves and accompanying coastal damage in the winter season were also repeatedly reported on the west coast of Japan, or the other 
side of the East Sea. The most remarkable event in recent decades occurred on 24 February 2008, highlighted by the peak significant wave height of $9.92 \mathrm{~m}$ at Toyama Bay and consequent severe damage of coastal facilities around the bay (Nagai et al., 2009; Mase et al., 2009; Lee et al., 2010).

Several researchers have studied the generation mechanism and characteristics of the winter storm waves in the East Sea (Kitaide, 1952; Isozaki, 1971; Isozaki and Yoshio, 1972; Jeong et al., 2009; Kim and Lee, 2010; Oh et al., 2010; Lee, 2013). According to them, such severe storms are likely to appear when the sea surface experiences continuously blowing strong winds, which are generated by an exceptionally well-developed, extra-tropical low pressure system staying over Hokkaido, near the northeastern boundary of the East Sea. Due to the long fetch distance from the low pressure system to the coasts of Korea and Japan, a thousand kilometers or more, the waves can become developed if the strong wind fields continue for several days over the sea. Unless there are any other focused wind events during the wave propagation to the coastal zone, the characteristics of the waves are likely to be those of long-period swells. However, the waves occasionally face varying weather conditions that may significantly influence the original wave characteristics. Hence, the wave field at its arrival on the coast is often presumed to be a combined sea, or a mixture of swell and wind waves. Indeed, the term swell-like waves is widely used among the researchers, news reporters, and local citizens, although the word carries rather vague connotation.

As described in Oh et al. (2010), the heights of such high waves often exceed $4-5 \mathrm{~m}$ and their spectrum is rather widebanded, whereas the swells coming to Korea's east coast are typically smaller than $3 \mathrm{~m}$ and follow a narrow-banded wave spectrum. Meanwhile, the significant wave period of the high waves mostly ranges between 9 and $14 \mathrm{~s}$, which is apparently longer than a typical wave period of wind sea. In this respect, the waves appearing in the winter season, having a comparatively longer period $\left(T_{\mathrm{s}}>9 \mathrm{~s}\right)$ and larger height $\left(H_{\mathrm{s}}>3 \mathrm{~m}\right)$, are widely called swell-like waves in Korea. If strong wind fields driven by a low pressure system are formed close to the coastal zone, the corresponding wave characteristics tend to be similar to those of wind waves, but if they are located at a rather longer distance from the coastline, the incoming waves are more likely to be dominated by swells. As the low pressure system evolves and moves across the East Sea, however, the wind fields over the sea are also subject to some spatiotemporal changes. Hence, the nature of swell-like waves is neither solely governed by swell or wind sea in most cases, for which explicit decomposition of both components from the wave record is not always simple.

At present, the occurrence of such high swell-like waves on Korea's east coast is only roughly predicted in the daily weather forecast. Hence, it is necessary to improve understanding of the detailed generation mechanism of high waves in order to accurately predict their arrival on the coast. As a fundamental step towards this, the Korea Institute of Ocean
Science and Technology (KIOST) has continuously monitored nearshore wave climate at multiple locations along the east coast of Korea during recent several years. These wave monitoring data are very precious because there had previously been no intensive wave observation program solely focused on the high waves occurring on Korea's east coast. This paper presents the principal monitoring results of the swell-like wave phenomena during the field observation period, particularly focusing on the intrinsic characteristics of the waves.

\section{Observed high swell-like waves}

\subsection{Wave observation at multiple stations}

The coastal waves were measured at nine locations along the east coast of Korea as shown in Fig. 1. At each measurement station, a pressure type wave gauge was deployed on the sea bottom. The water depths at the measurement stations varied between 13.0 and $18.5 \mathrm{~m}$ as shown in Table 1. Considering that the typical significant wave period of the high waves ranges from 9 to $14 \mathrm{~s}$, most of the waves measured at the stations tend to be intermediate depth waves. The values of relative depth $k h$ computed from the wave observation data are in the range from 0.5 to 1.0. As the bathymetric contours in this area are straight and parallel to the shoreline, the incoming waves may experience refraction, shoaling and possible breaking when they feel the sea bottom, but amplification of wave height due to wave focusing rarely occurs. Also, the relatively steep bathymetric gradient allows propagation of waves from the offshore to the nearshore without undergoing strong wave breaking. Hence, the significant wave height observed at the wave station is not so much different from the one offshore in most cases.

The pressure sensors at the nine stations were not installed at the same time, but the number of active measurement stations has increased year by year with slight adjustments in the sensor specification and the method of data acquisition. Since around the year 2008, continuous wave observation has been carried out at all locations shown in Fig. 1. Moreover, two more devices for identifying wave direction were added very recently to the above wave observation network: a Directional Wave Rider (DWR) buoy was installed adjacent to the pressure gauge at Jukbyeon in March 2009, while an Acoustic WAve and Current profiler (AWAC) at Sokcho in December 2010, respectively.

The raw wave data were acquired at the sampling rate of $2 \mathrm{~Hz}$, except the buoy that adopted a $1.28 \mathrm{~Hz}$ rate. For each measuring instrument, the wave spectra were obtained every 30 min by using the first 2048 data points within the time segment. Then, the corresponding significant wave height $\left(H_{\mathrm{S}}\right)$ was estimated using the zeroth moment of the spectrum $\left(m_{\mathrm{o}}\right)$ as $H_{\mathrm{s}}=4\left(m_{\mathrm{o}}\right)^{1 / 2}$. The values of $H_{\mathrm{S}}$ were also computed from the zero-upcrossing method by taking the mean 
Table 1. Geographic coordinates and water depths of the measurement stations.

\begin{tabular}{llll}
\hline Station & Latitude & Longitude & $\begin{array}{l}\text { Water } \\
\text { depth }(\mathrm{m})\end{array}$ \\
\hline Daejin & $38.521^{\circ} \mathrm{N}$ & $128.427^{\circ} \mathrm{E}$ & 17.5 \\
Sokcho & $38.208^{\circ} \mathrm{N}$ & $128.617^{\circ} \mathrm{E}$ & 18.5 \\
Gangneung & $37.798^{\circ} \mathrm{N}$ & $128.929^{\circ} \mathrm{E}$ & 13.0 \\
Mukho & $37.548^{\circ} \mathrm{N}$ & $129.125^{\circ} \mathrm{E}$ & 15.0 \\
Jukbyeon & $37.060^{\circ} \mathrm{N}$ & $129.433^{\circ} \mathrm{E}$ & 18.0 \\
Hupo & $36.700^{\circ} \mathrm{N}$ & $129.484^{\circ} \mathrm{E}$ & 15.0 \\
Weolpo & $36.212^{\circ} \mathrm{N}$ & $129.398^{\circ} \mathrm{E}$ & 17.4 \\
Yangpo & $35.886^{\circ} \mathrm{N}$ & $129.539^{\circ} \mathrm{E}$ & 17.8 \\
Jinha & $35.387^{\circ} \mathrm{N}$ & $129.361^{\circ} \mathrm{E}$ & 18.0 \\
\hline
\end{tabular}

of the highest one-third waves during the same time segment and the agreement was in general fairly good when they were compared with the corresponding spectral estimates. For the wave period, meanwhile, the significant wave period $T_{\mathrm{S}}$ estimated from the zero-upcrossing method was used in the analysis as the quantity displayed the temporal changes of the wave period more effectively rather than some other parameters such as the peak period $\left(T_{\mathrm{p}}\right)$ or the mean period $\left(T_{\mathrm{m}}\right)$ derived from the wave spectrum. The values of $T_{\mathrm{p}}$ were sometimes unreasonably estimated, especially when the wave height was relatively small, whereas $T_{\mathrm{m}}$ was less sensitive to the steep rise or subtle change of wave period than $T_{\mathrm{s}}$.

\subsection{High waves on 1 January 2011}

As an exemplary observation record of high waves, the time series of $H_{\mathrm{s}}$ at nine stations during the high wave events that occurred between 31 December 2010 and 04 January 2011 are shown in Fig. 2. The rapid increase of wave heights on the first day of 2011 is clearly displayed in the figure. The wave height reached its maximum at 07:30 KST at the most northern station, Daejin, while it appeared $7 \mathrm{~h}$ later at the most southern station, Jinha. KST denotes Korea Standard Time, which is $9 \mathrm{~h}$ ahead of Coordinated Universal Time (UTC). In general, the wave height first started to increase at the stations of high latitudes. The largest wave height during the time period shown in Fig. 2 was $6.71 \mathrm{~m}$, which was measured at 09:30 KST on 1 January at the Jukbyeon station. Almost similar maximum wave heights of $6.70 \mathrm{~m}$ were also observed at the Gangneung station.

Similar to the trends of $H_{\mathrm{s}}$, the significant wave period also increased and then decreased monotonously around the first day of 2011 as shown in Fig. 3. Contrary to the time series of $H_{\mathrm{s}}$ shown in Fig. 2, however, the rapid rise in the magnitude of the quantity was less apparent in case of $T_{\mathrm{s}}$. This was mainly because of the relatively long significant wave period of approximately $8-10 \mathrm{~s}$, before the further increase of wave period up to approximately $12-13 \mathrm{~s}$ on 1 Janurary,

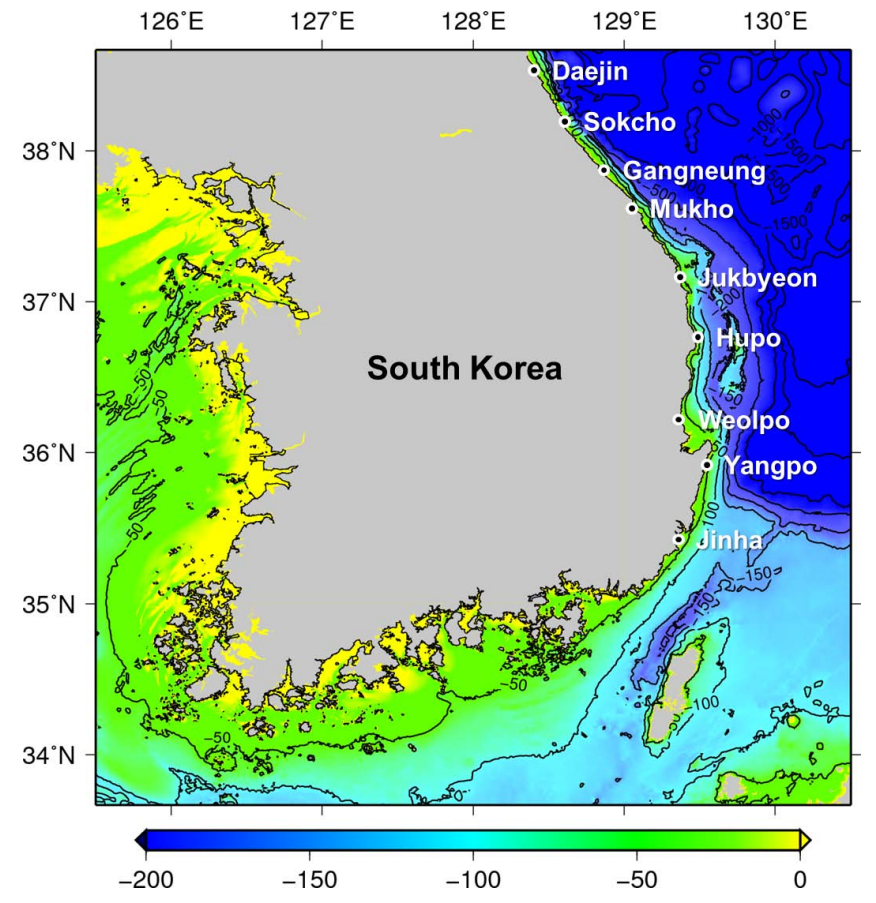

Fig. 1. Location map of the nine wave measurement stations.

influenced by precedent swell waves. For most of the other high wave events, an abrupt jump was more clearly recognized with the first passage of high waves since the wave period before the arrival of high waves was much shorter, typically from around 5 to $7 \mathrm{~s}$ (see Fig. 4).

\subsection{Comparison of three high wave event records}

From the continuous observation and subsequent analysis during many years, it became obvious that the general features of the onset and continuation of the high wave events show apparent distinction among them. In order to highlight such a difference in the temporal change of wave heights and periods, time series of $H_{\mathrm{S}}$ and $T_{\mathrm{S}}$ obtained during two more high wave events were presented in Fig. 4 for the comparison with the data shown in Figs. 2 and 3. For the clarity of the comparison, only the wave records obtained at the four stations of Sokcho, Mukho, Hupo, and Jinha, which almost covers the whole eastern coastline of Korea with an almost equivalent spatial interval in latitude, are displayed in the figures. Similar plots as in the top two panels of Fig. 4 are also shown in the bottom two panels of Fig. 4 for the high wave event in January 2011.

A similarity among the three cases shown in Fig. 4 is the sequential rise of the wave height, starting from the most northern station followed one after another at the next southern stations. The rising time of the wave height gradually fell behind with the decrease in the latitude of the measurement station. This implies that the waves might have propagated from the northward direction in all the cases. 

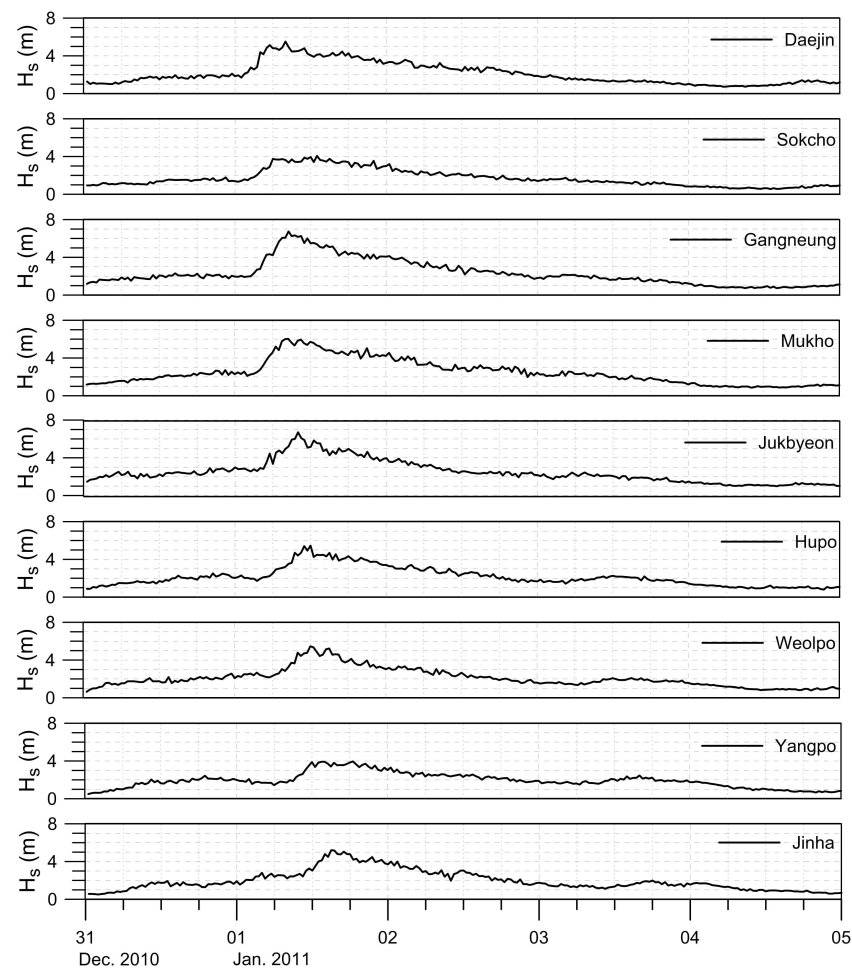

Fig. 2. Time histories of $H_{\mathrm{S}}$ from 31 December 2010 to 4 January 2011 observed at the nine measurement stations.

Meanwhile, the maximum wave heights in the three cases showed marked difference among them. On 23 October 2006, exceptionally high waves greater than $9 \mathrm{~m}$ were observed at the relatively northerly located stations of Sokcho and Mukho. The $9.69 \mathrm{~m}$ wave record at Sokcho at 11:00 KST on 23 October was and is still the largest significant wave height observed on the eastern coastline of Korea. In contrast, the maximum heights on 24 February 2008 as well as 1 January 2011 were not as high as the one in October 2006, $5.06 \mathrm{~m}$ and $6.04 \mathrm{~m}$ respectively, at the stations of Mukho. Another difference among the three time series is the overall trend of $H_{\mathrm{S}}$ during the high waves. In the cases of October 2006 and January 2011, the wave height rapidly increased and monotonously decreased over more than two days. In the case of February 2008, however, the wave height further increased on 24 February after the first jump on the previous day so that it showed a double-peaked pattern as seen in the figure.

The corresponding time series of $T_{\mathrm{S}}$ also displayed a similar difference among the three wave events as with those of $H_{\mathrm{s}}$. In general, the significant wave period increased along with the arrival of high waves and then gradually decreased after the peaks, but the detailed patterns of change in $T_{\mathrm{S}}$ appeared different from each other. Compared to the other two cases, the value of $T_{\mathrm{s}}$ increased exceptionally sharply in October 2006. The time series in February 2008 is characterized with the rise of $T_{\mathrm{S}}$ in double times, which is related to
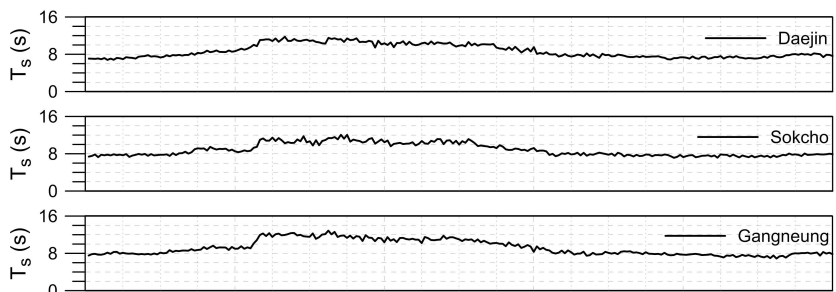

$\stackrel{0}{0}_{0}^{16}{ }_{0}^{16}$
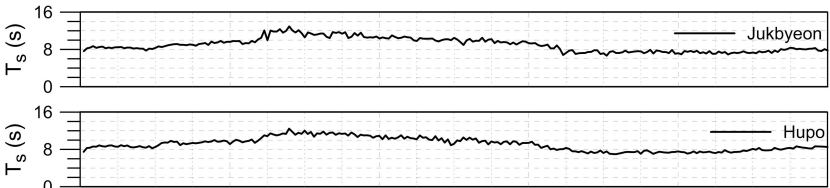

${ }_{0}^{\infty}{ }_{0}^{16}{ }_{0}$
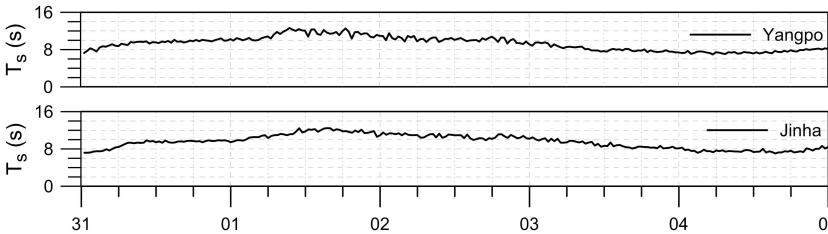

Dec. 2010 Jan. 2011

Fig. 3. Time histories of $T_{\mathrm{S}}$ from 31 December 2010 to 4 January 2011 observed at the nine measurement stations.

the double-peaked pattern of the corresponding time series of $H_{\mathrm{s}}$. The noticeable feature in January 2011 is the little temporal gap in arrival times at different measurement stations.

Further difference was found in terms of the intervals between arrival times of the high waves at the four stations. The high waves started to occur at Sokcho at 17:00 KST, 22 October 2006, while they arrived at Jinha approximately $22 \mathrm{~h}$ late. In contrast, the gap in arrival time of the high waves between the two stations (Sokcho and Jinha) was only approximately half in January 2011 and one-third in February 2008, respectively.

\section{Some characteristics of the high swell-like waves}

\subsection{Spatial difference in wave appearance and growth}

As shown above, temporal gaps in the onset of high waves among the measurement stations showed an apparent discrepancy depending on each wave record. Moreover, the spatial distributions of the maximum wave height along the stations were also not the same for the three wave events. Since these two features are fundamental factors in estimating the source region and propagation direction of the high waves, they were investigated in more detail by utilizing all the available wave data for the three cases as explained in the following. 

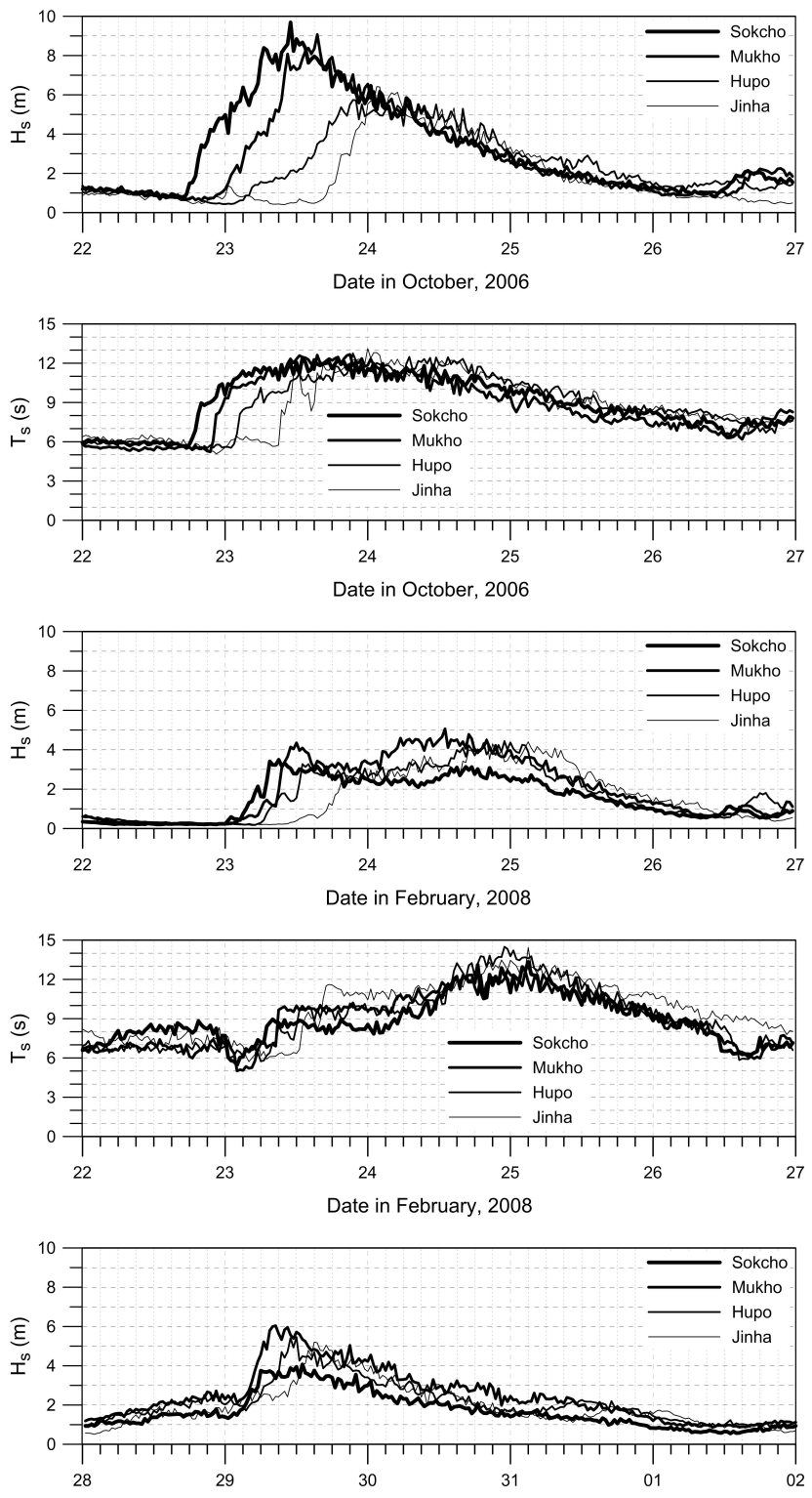

Date in December, 2010

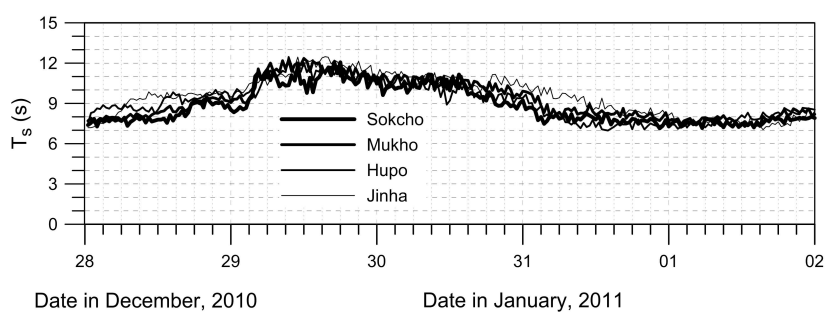

Fig. 4. Comparison of changes in $H_{\mathrm{S}}$ and $T_{\mathrm{S}}$ at the four measurement stations during the high wave events in October 2006, February 2008, and January 2011.

In Fig. 5, the two time instances at the steep initial rise and peak of the wave height detected at each measurement station are displayed as the left and right ends of the corresponding bar graphs, respectively. Hence, the horizontal length of each

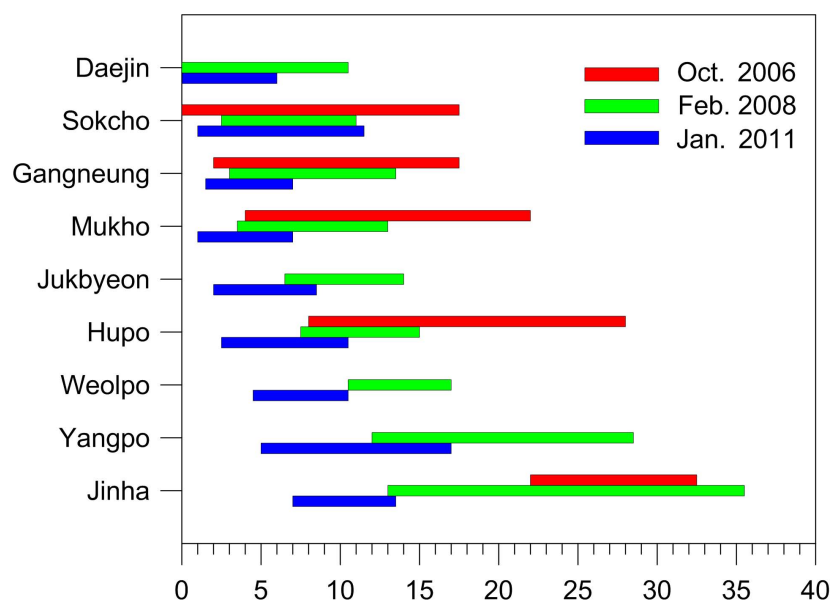

Time elapsed after the arrival of first wave (hr)

Fig. 5. Temporal duration between the time instances at the first appearance and at the point of reaching maximum height at each measurement station. The abscissa indicates the time elapsed from the first arrival of the high waves at any of the nine stations.

bar graph stands for the time span from the first appearance of the high waves to the point of reaching maximum wave height. In the figure, the abscissa indicates the time elapsed measured from the first arrival of the high waves at any of the nine stations, which were typically observed at the most northern available stations. As shown in Fig. 5, the first arrival time of the high waves was more delayed in general if the latitude of a station was lower. The same trend was also found in the appearance of maximum wave height along the measurement stations. These features imply that the high waves came from the northern side as mentioned earlier. For the three wave events, temporal gaps in the first appearance of the high waves between the most northern and southern stations were 22,13 , and $7 \mathrm{~h}$ respectively, showing marked discrepancies.

Meanwhile, the time span from the initial rise to the arrival of peak wave was on average $16.3 \mathrm{~h}$ in October 2006. The corresponding mean duration time for the waves in February 2008 was $8.6 \mathrm{~h}$, much shorter compared to the previous case, when it was calculated by excluding data from the two lowest stations (Yangpo and Jinha). At those stations, the first peak appearance times were rather ambiguously estimated as the decreasing and re-increasing trend after the first peak was not clearly found as at the rest of the stations. Finally, in case of the high waves that occurred in January 2011, it took only on average $7.4 \mathrm{~h}$ to reach the maximum height after the initial arrival of high waves.

Figure 6 shows the maximum significant wave heights at the measurement stations during the three high wave occurrences. In the case of February 2008, maximum wave heights at each station during the first and second rising periods are presented in the figure, respectively (See Fig. 4). Although a 


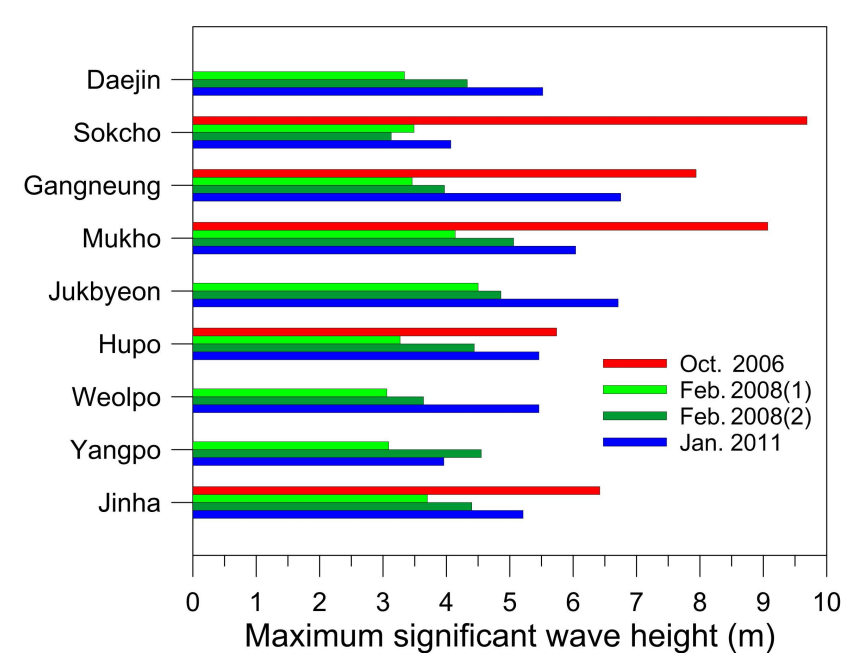

Fig. 6. Maximum significant wave heights observed at each measurement station. The two maximum heights in February 2008 correspond to the value during the first and second wave growth periods, respectively.

general similarity in the spatial distribution of the maximum height is not found among the three cases, it is clear that the highest height in a single wave event is typically observed between Sokcho and Jukbyeon stations, or the central part of Korea's east coast.

\subsection{Wave spectra}

Figure 7 shows the wave spectra that correspond to the maximum wave height during the three high wave events in October 2006, February 2008, and January 2011. Although the spectral magnitudes were different for each case, the overall shapes of the wave spectra were almost the same in spite of the difference in observation stations and time periods. This implies that the general shape of the wave spectrum, formed by the high waves occurring on the east coast of Korea, would always be similar to those shown in Fig. 7. For all the cases, the spectral peak frequency was in the range of $f=0.07 \sim 0.08 \mathrm{~Hz}$, equivalent to a peak wave period of $12 \sim 14 \mathrm{~s}$. Although it is not shown in the figure, investigating temporal change of the wave spectrum revealed that the spectral energy growth during the high swell event was particularly concentrated over the peak frequency bands. Meanwhile, the secondary spectral peak also appeared at $f=0.15 \sim 0.2 \mathrm{~Hz}$ for all cases, which could be a result of self-wave interaction activated under strong wind forcing (Hasselmann et al., 1962; Suh et al., 2000). Overall, the spectral energy of the secondary peak was one order of magnitude smaller than that of the first peak.

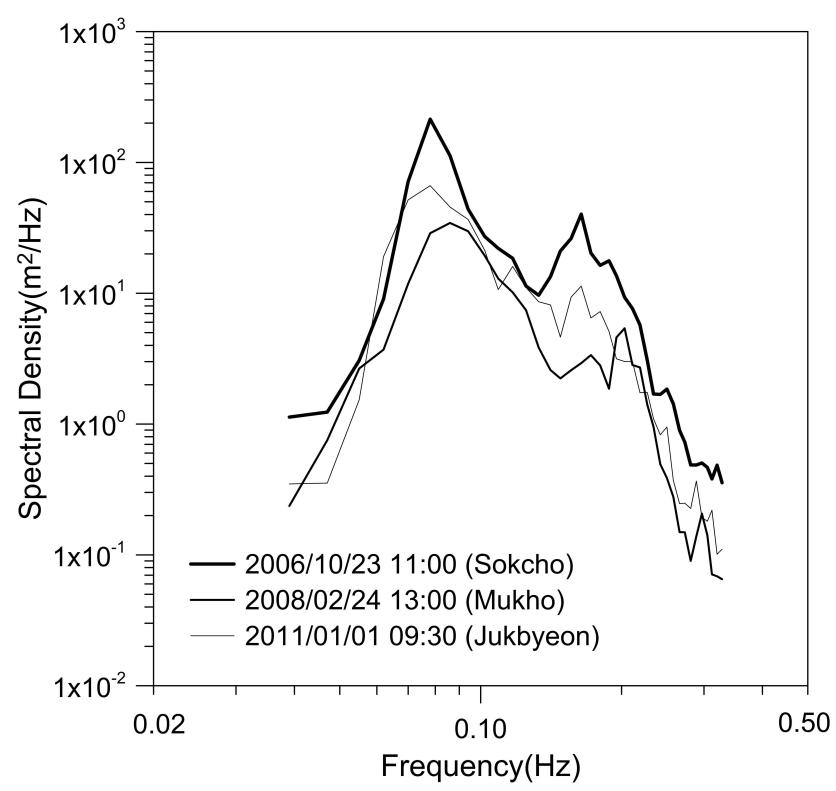

Fig. 7. Wave spectra corresponding to the highest wave height for the three high wave events.

\section{Analysis of the meteorological conditions}

\subsection{Meteorological data}

In order to assist the investigation of the generation mechanism of the high waves, the meteorological data provided by the Korean Meteorological Agency (KMA) were used in the analysis. First, the weather charts around the Korean Peninsula during the occurrence of high waves were collected. In addition, the data of mean wind speed and direction were gathered at the weather stations that are closest to each of the nine wave measurement locations shown in Fig. 1 respectively. All the weather stations are located at inland locations that are very close to the coastline. KMA provides the weather chart every $3 \mathrm{~h}$, while the mean wind data are produced at every $1 \mathrm{~h}$ interval. They estimate the mean wind speed and direction by taking the average of the corresponding instantaneous values during the first 10 min every hour. Since the vertical distance of the anemometer from the earth surface is not the same among the weather stations, the mean wind speed at each station was converted to the value at $10 \mathrm{~m}$ above the earth surface by assuming a logarithmic profile of it.

\subsection{Development and evolution of strong low pressure system}

In order to understand principal meteorological features associated with the high waves that occurred in January 2011, the weather charts during the time period of high wave occurrence were investigated. Figure 8 shows three weather charts corresponding to two and one day before, and on the day 
of the first wave occurrence on the east coast of Korea. At 09:00 KST on 30 December 2010, a low pressure system was formed in the central lower region of the East Sea as can be seen in the top panel of Fig. 8. During the next $24 \mathrm{~h}$, the center of the low pressure system moved eastward across Japan's main island, with its central atmospheric pressure dropping by $14 \mathrm{hPa}$. Then, the central atmospheric pressure further dropped to $972 \mathrm{hPa}$ when it moved more east off the Japan islands at 09:00 KST on 1 January 2011. As shown in the middle and bottom panels of Fig. 8, the spatial distance between the isobaric lines across the East Sea is very narrow in the contour maps of the atmospheric pressure field. This implies that the pressure gradient was very steep perpendicular to the isobaric lines, which might be closely associated with the strong winds and resulting generation of high waves over the sea. The contour maps of the atmospheric pressure indicate that wind might blow from the northeastern direction, as wind fields are typically formed along the isobaric lines clockwise to the low pressure center. Such strong northeasters blowing over the East Sea in the winter season have been designated as Donghae twisters in Korea (Chung, 1996).

Although Fig. 8 shows only the weather charts at three instants during the occurrence of high waves in January 2011, the formation of such strong low pressures and resulting steep pressure gradient across the sea were always confirmed during the occurrence of high wave events. Since KMA provides weather charts every $3 \mathrm{~h}$, it is possible to investigate the moving path of an individual low pressure by following its central location. In fact, the center of an extra-tropical low pressure system is not always easily recognizable because the central location may vary greatly according to the overall pressure field surrounding it. During the high wave events on the east coast of Korea, however, the central location of the low pressure system can be relatively clearly identified by sight in the corresponding weather chart, as already shown in Fig. 8. For the three high wave events, the identified moving trajectories of the low pressures are shown in Fig. 9. In the figure, the location of each circle stands for the central location of the low pressure system, while the numbers in it indicate the time difference measured from the first arrival time of the waves on the east coast of Korea. The central locations of the low pressure system were obtained one by one from every single corresponding weather chart by finding the exact center of the circled isobaric lines. Then, each found location was carefully marked in the map as shown in Fig. 9 referring to the neighboring latitude/longitude lines. Before and during the occurrence of the high waves in October 2006, there existed two low pressure systems around the Yellow Sea, which later combined into one. In February 2008, two low pressure systems were also developed in the East Sea, but their traces were independent of each other in this case.

A common feature found in Fig. 9 is that the low pressure systems advanced eastward in all cases. However, the specific location, or latitudes and longitudes of the low pressure
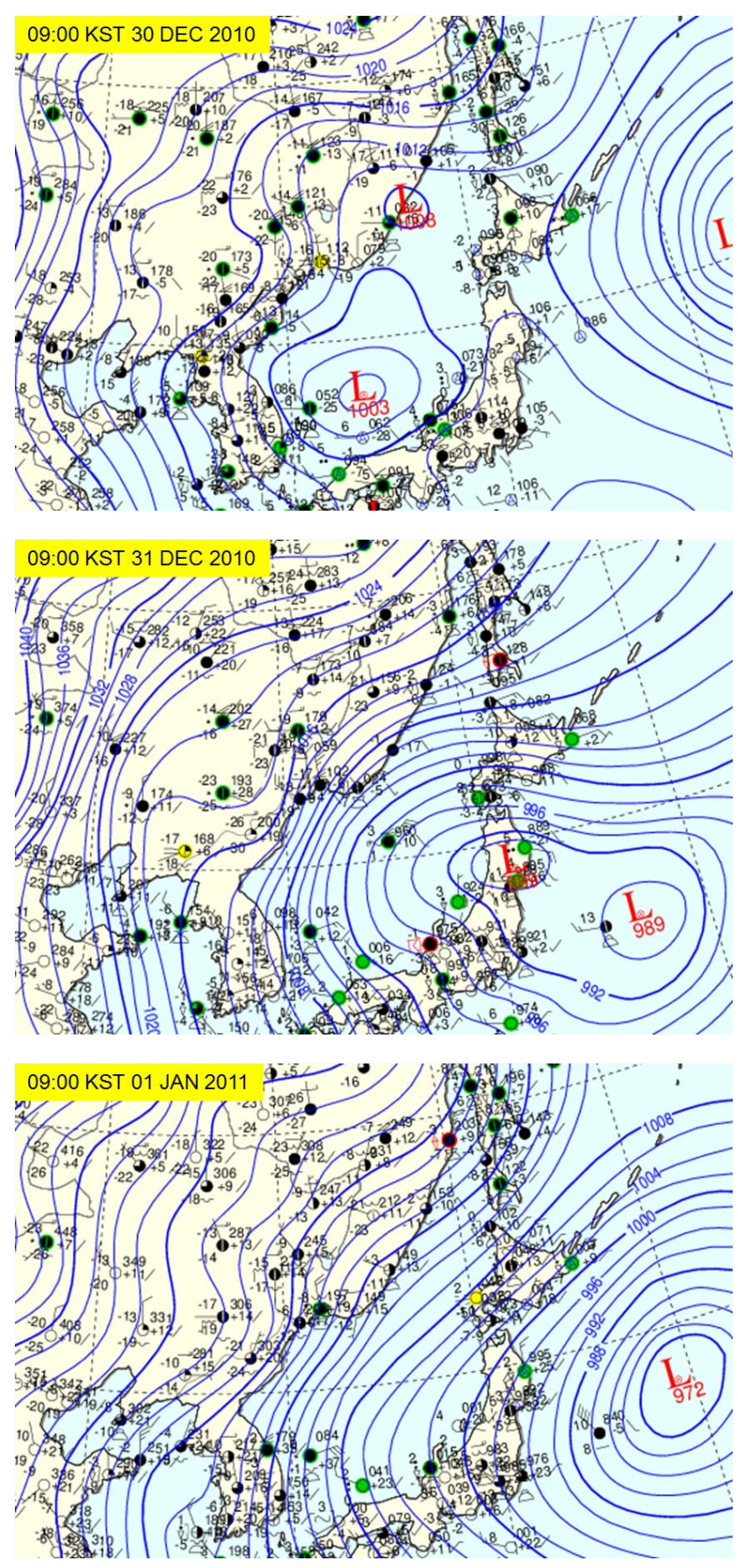

Fig. 8. Three weather charts at 09:00 KST (Korea Standard Time) on 30 and 31 December 2010 and 1 January 2011. They correspond to two and one day before, and on the day of first wave arrival on the east coast of Korea.

centers, associated with the respective wave events, showed significant differences depending on the individual case. For example, the location on the time when the first waves arrived on the coastline, or the position of the circle labeled as zero in Fig. 9, was very different among the cases. It was on the west coast of the Korean Peninsula for each of the two 


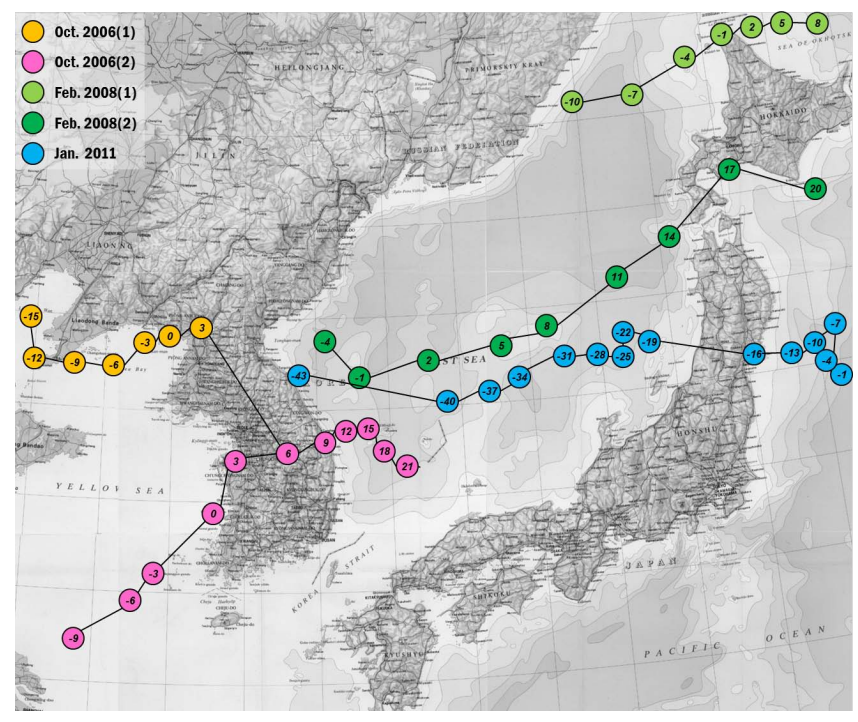

Fig. 9. The paths following the center of the low pressures at the time of the three high wave events. The numbers in circles indicate the time difference in hours counted from the first arrival time of the corresponding high waves on the east coast of Korea.

pressure systems in October 2006, but on the far east side of Japan's main island for the low pressure in January 2011. At the time of the first rise of wave height in February 2008, the centers of the two low pressures were placed at the northern tip of Hokkaido and the western central region of the East Sea, respectively. In this respect, there seems to be little consistency in the relationship between the occurrence of high waves and the detailed moving path of the corresponding low pressure system.

\subsection{Pressure drop and magnitude of waves}

As explained in Fig. 8, the central atmospheric pressure typically drops along with the advance of a low pressure system into the sea. The reason for this tendency is ascribed to the acquisition of more sea vapors, energy source promoting growth of a low pressure, with its continuous eastward movement toward the Pacific Ocean. Figure 10 shows the change in atmospheric pressure at the center of the low pressure systems associated with the three high wave events. In the figure, the horizontal axis denotes the relative time counted from the first arrival of waves on the coast. It can clearly be seen that the central pressure dropped along with the time passage for all the cases. However, the initiation time and the magnitude of the pressure drop showed some difference depending on the cases. In the case of January 2011, the decline of atmospheric pressure started to occur $48 \mathrm{~h}$ before the arrival of waves on the coast. Moreover, the total amount of pressure drop during the period exceeded $30 \mathrm{hPa}$. Such a rapid atmospheric pressure drop during a similar high wave event in April 2012 was also reported in Lee (2013). In contrast, the pressure decline begins only less than $15 \mathrm{~h}$ before the ap-

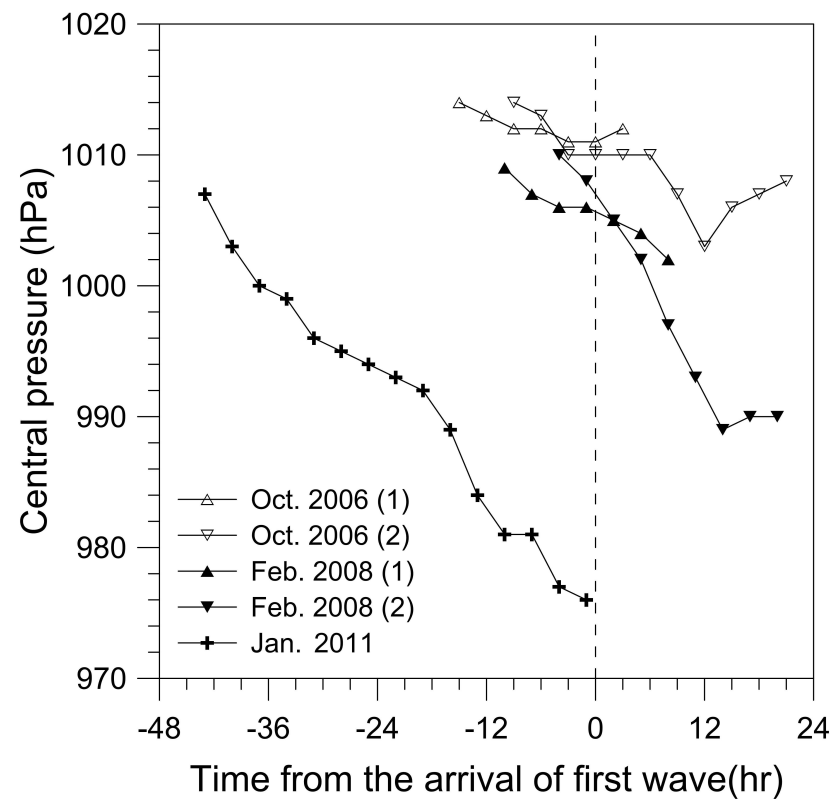

Fig. 10. Variations of atmospheric pressure at the center of the low pressures along with their movement. The vertical dashed line in the figure corresponds to the first arrival time of waves on the east coast of Korea for each high wave event.

pearance of the first wave for the other cases, with smaller magnitudes of pressure drops.

Particularly in October 2006, the central pressure showed comparatively insignificant pressure change, except for some drop of the secondly generated low pressure system that was initiated $6 \mathrm{~h}$ later than the first wave arrival. This feature is contradictory to the appearance of the highest significant wave height of $9.69 \mathrm{~m}$ at Sokcho during that period. In order to find the reason for this mismatch, we examined a series of sequential weather charts during the wave event in October 2006. Through the examination, it was clarified that the weather conditions were favorable for the generation of a strong wind field heading towards Korea because the two low pressures formed at that time moved slowly and stayed half a day around the Yellow Sea and inland of the Korean Peninsula, although the pressure drop itself was relatively smaller than those of the two low pressures in February 2008 and January 2011. Moreover, the existence of a strong high pressure system, whose central pressure was greater than $1030 \mathrm{hPa}$, and located north to the Korean peninsula helped the formation of a strong pressure gradient in the north-south direction toward Korea. In contrast, the reason for a comparatively smaller maximum height during the wave events in February 2008 and January 2011, notwithstanding the greater pressure drop in both cases, was ascribed to more eastwardly biased locations of the corresponding low pressure systems far offshore from Korea.

One noteworthy observation is that extremely high waves of $9.92 \mathrm{~m}$, comparable to those observed at Sokcho in 
October 2006, incurred huge damages along the central northern coast of Japan around Toyama Bay on 24 February 2008. At that time, a pair of low pressure systems had developed in the East Sea as shown in Fig. 9, which made strong wind fields heading to the Japanese western coastline and resulting in high waves that were observed around Toyama Bay. Interestingly, huge waves struck the east coast of Korea when the two low pressures were formed around Korea in October 2006 and almost the same wave phenomenon due to another two low pressures was observed on the central northern area of Japan's west coast in February 2008. This implies that independent generation and coincident development of two or more extra-tropical low pressure systems yield a favorable condition for the formation of a large wave field. Eventually, however, the height, direction, and continuation time of waves would be determined by the combination of all the relevant meteorologic and ocean conditions, such as the amount of pressure drop, moving trajectory, staying time, and the number of low pressure systems as well as the overall arrangement of neighboring atmospheric pressure field. Therefore, there seems to be no simple direct relationship between the magnitude of waves and the pressure drop of related low pressure systems, although the generation and evolution of such a low pressure was always confirmed when a high wave event occurred on Korea's east coast.

\subsection{Cross-comparison of wind and wave fields}

Figure 11 presents time histories of mean wind speeds and directions during the three high wave events in October 2006, February 2008, and January 2011. The values of significant wave heights are also shown in the figure in order to examine the relationship between the local wind fields and the high wave events. Note that the values of $H_{\mathrm{s}}$ are doubled in Fig. 11 to help easy comparison of both quantities in a single plot; it shows the wind records acquired at the weather stations closest to the wave observation stations where the maximum wave heights were measured. Each data point in Fig. 11 represents the mean of instantaneous values during the first $10 \mathrm{~min}$ of every hour so that the time interval of wind data was $1 \mathrm{~h}$. Relatively high mean wind speeds surpassing $15 \mathrm{~m} \mathrm{~s}^{-1}$ were observed on 23 October 2006 and 1 January 2011. In contrast, the mean wind speeds were lower than $10 \mathrm{~m} \mathrm{~s}^{-1}$ from 22 to 26 February 2008. This indirectly implies that the local wind field at the weather stations was not necessarily significant in generating the high waves at that time.

The time instances corresponding to each peak of the mean wind speed and the significant wave height coincided well in October 2006 and January 2011, but this trend was not found in February 2008. Even in the case of October 2006, significant wave height started to increase at 17:00 KST on 22 October before the more sharp increase of wind speed at 03:00 KST the next day. In this respect, the occurrence of high waves was not directly correlated with the local wind
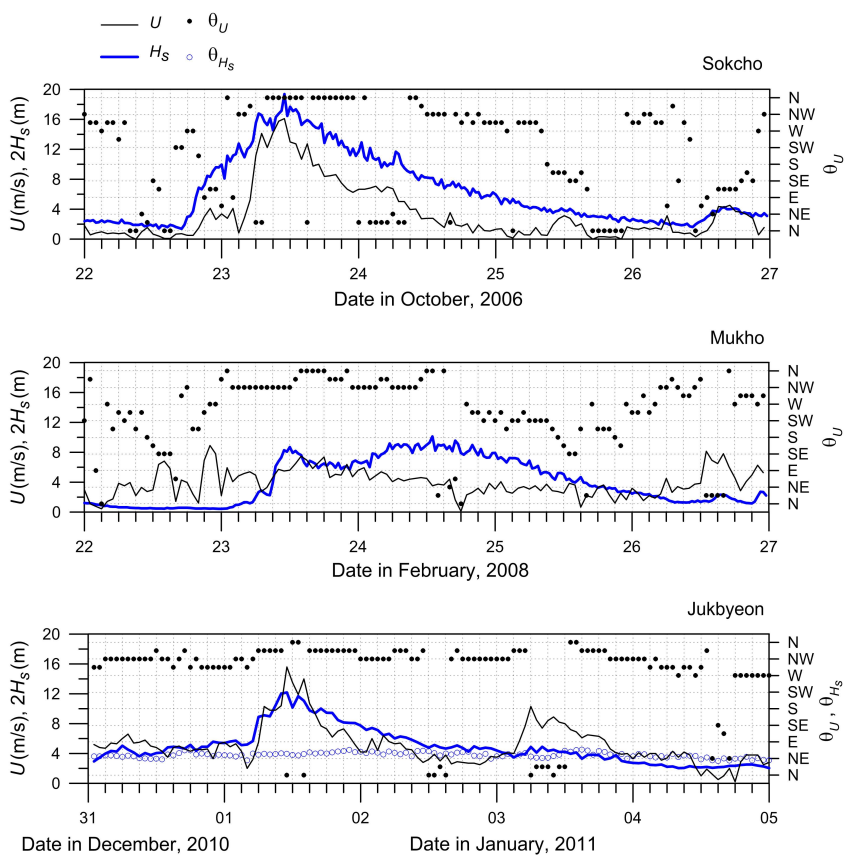

Fig. 11. Comparison of time histories of wind speeds and wave heights during the three high wave events. Temporal variations of direction in wind and waves (only bottom panel) are also shown in the figure.

field, although strong local winds affected the more rapid increase of wave height during the wave event. Recent human casualties occurred mostly when local wind speeds were not so strong, as in the case of February 2008. As the local weather and wind conditions were mild on those days, tourists or fishermen were likely to do their coastal activities without recognizing the danger of sudden high waves occurring.

Meanwhile, the wave directions during the high wave event that occurred in January 2011 were also shown in the bottom panel of Fig. 11, as the quantity could be measured since March 2009 (see Sect. 2.1). As opposed to the rapid increase and subsequent decrease in wave height for five days shown in the figure, the wave direction changed very little within the narrow range from east to northeast. This implies that the wave field during the five days was wholly governed by a single dominant wave phenomenon. When the mean values of wave direction measured at Jukbyeon were compared with that at Sokcho, it was slightly more northward at Jukbyeon $\left(54.6^{\circ}\right.$ at Jukbyeon whereas $67.4^{\circ}$ at Sokcho to the north). Since the wave angle at the station of lower latitude was more inclined to the north direction, it is possible to presume that the source region of the high waves might be located at a northeastern area from both stations.

In contrast, the wind directions at the weather stations were mostly classified into north to northwest groups during the three wave events, as seen in Fig. 11, although there were some scatters occasionally. Hence, northeasters directly 
influencing the high wave events might blow over the far offshore sea off Korea's east coast. This fact again confirms that the local wind field itself was not a major source of generating the high waves observed on the coast.

\section{Emergence and propagation of high swell-like waves}

\subsection{Estimation of the source region of waves}

If a wave field is solely composed of a swell component, it is possible to estimate the source region of waves based on the difference in propagation speeds of wave components related to different spectral frequencies (Earle et al., 1984). Assuming a swell wave starts its propagation at the time $t_{0}$ and reaches a location at the time $t_{\mathrm{a}}$ after traveling a distance $D$, the relationship between the three parameters is given as follows:

$t_{0}=t_{\mathrm{a}}+\frac{D}{g / 4 \pi f}$,

where $g$ is the gravitational acceleration and $f$ is the wave frequency. After differentiating Eq. (1) and rearranging with respect to $D$ we obtain

$D=\frac{\mathrm{g}}{4 \pi}\left(\frac{t_{2}-t_{1}}{f_{2}-f_{1}}\right)$,

where $t_{1}$ and $t_{2}$ denote the arrival time of wave components corresponding to $f_{1}$ and $f_{2}$, respectively. Hence, the traveling distance $D$ can be simply estimated if there exists a discrepancy between the arrival times of wave components having different frequencies. Then, the initiation time of swell propagation $t_{0}$ is also known by inserting $D$ into Eq. (1).

By using the above method, values of $D$ and $t_{0}$ were evaluated for the three high wave events shown in Fig. 4. For the wave records at Sokcho where high waves arrive first, among the four stations shown in the figure, the time series of three individual wave components $f=0.070,0.078$, and $0.086 \mathrm{~Hz}$ were plotted together as shown in Fig. 12. The three frequencies correspond to a significant wave period of 11-13.5 s. For the maximum wave spectra for the three wave events, the spectral peak frequency mostly matched with one of the above three frequencies. In the figure, only the result for the high waves that occurred in February 2008 is provided because the second rise of wave height during the wave event was adequate for applying the method of Earle et al. (1984), while the other two high wave events in October 2006 and January 2011 were found to be not applicable to the above analysis method.

In Fig. 12 it is recognized that spectral energies of the three wave components start to increase almost simultaneously at the first rising of wave height at 02:00 KST on 23 February. The dashed line at this time shown in the figure is plotted by connecting and extending the initial rising times of the three wave components. The line is almost vertical as

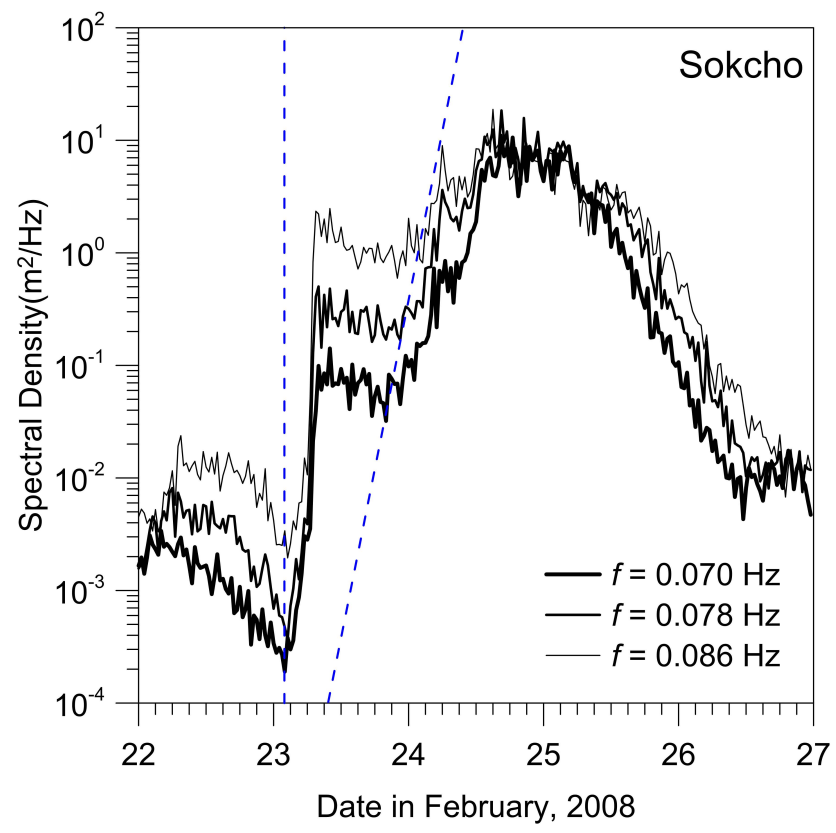

Fig. 12. Time series of spectral densities for the three individual wave components whose frequencies are $0.070,0.078$, and $0.086 \mathrm{~Hz}$, respectively.

there is no significant difference in the rising times among them. In such a condition, it is not possible to estimate $D$ and $t_{0}$ because $D$ goes to infinity as $f_{2}-f_{1}$ is almost zero in Eq. (1). In contrast, an apparent discrepancy is found between the starting times of the three wave components during further increase of spectral densities in the evening of 23 February. The spectral energy at the lowest frequency component $(f=0.070 \mathrm{~Hz})$ first starts to increase at 20:00 KST on 23 February. The rising of spectral energy occurs two and half hours later for the wave component of $f=0.078 \mathrm{~Hz}$, while six and half hours later for the one $f=0.086 \mathrm{~Hz}$. In this condition, the dotted line connecting the corresponding rising times is not vertical but inclined as shown in the figure so that estimation of $D$ and $t_{0}$ is possible. After simple calculation, those values were evaluated as $D=965 \mathrm{~km}$ and $t_{0}=16: 00 \mathrm{KST}$ on 22 February. Considering that dominant wave direction during high wave occurrences on Korea's east coast is usually northeastern as shown in Fig. 11, the source region of the waves arriving after the evening of 23 February is conjectured to be the sea waters between Russia's east coast and Japan's Hokkaido island. In the weather chart provided by KMA, at 15:00 KST on 22 February, indeed, the center of the low pressure system was located very close to the estimated source region, indicating formation of strong wind fields around this area.

As the characteristics shown in Fig. 12 were quite different at the first and second rises of spectral densities, the evolution of wave spectra after the two time instances was compared to each other. Then, it was found that the spectral energy 
increased over almost all the frequency ranges of the wave spectra in the former case whereas the augmentation of spectral energy was limited to comparatively narrow frequency bands around the peak frequency in the latter case. Such a contrast indicates that the intrinsic wave growth mechanism would have distinct dissimilarity during the two time periods. Since swell waves are generally represented as a peaked, narrow wave spectrum, the characteristics of waves observed after the evening of 23 February would be predominantly governed by long-traveled swell. In contrast, the earlier wave growth from daybreak of the day was supposed to be a result of local wind sea development occurring near the wave station since the wave energy was enhanced not only for the peak frequency ranges but for the relatively lower and higher frequencies demonstrating active wind action on the wave field.

Meanwhile, Fig. 13 shows the time series of wave steepness at Sokcho station during the high wave event in February 2008. It is clearly seen that values of the wave steepness rapidly increase from daybreak of 23 February along with the first rising of wave height, similarly as in augmentation of spectral energy at that time shown in Fig. 12. In contrast, such a steep increase of the wave steepness is not found around the time of the second increase in spectral energy after the evening of 23 February. In that period, the wave steepness continuously decreases in spite of increase of the wave height. This discrepancy might be ascribed to the aforementioned difference in dominance of wave field by either wind sea or swell during the two time periods. It is noteworthy that the high waves observed in October 2006 and January 2011 also had similar patterns as in Figs. 12 and 13, with respect to the evolution of wave spectra as well as the variation of wave steepness associated with the first wave growth in February 2008 .

\subsection{Discussions on the estimation of wave source region}

The generation of high swell-like waves and their propagation to the east coast of Korea can be qualitatively understood from the analysis of wave observation data together with the corresponding meteorological condition during the wave occurrence. Furthermore, quantitative evaluation of the source region and the initial time of wave development can be made by using the method suggested by Earle et al. (1984). However, this method is only applicable to a swell-dominating wave field as it is basically based on the wave dispersion principle. Indeed, it was not possible to estimate the source region of high waves that occurred in October 2006 and January 2011 because the corresponding wave spectral features were similar to those of wind waves. The reason for inability to make use of the method of Earle et al. (1984) for wind sea is that wave components having different frequencies may not freely propagate according to their unique dispersion characteristic but forced to travel under the influence of continuous wind action (Hasselmann, 1962).

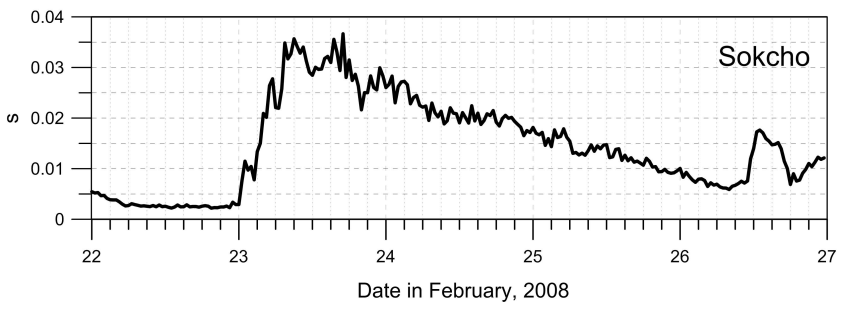

Fig. 13. Temporal variation of wave steepness during the high wave event in February 2008.

Another limitation in the estimation of wave source region based on the method of Earle et al. (1984) is that it intrinsically assumes a point source fixed at a specific spatial position during the whole time of swell propagation to a certain location. This kind of ideal swell propagating condition is scarcely met in the real field conditions as a low pressure system will move as shown in Fig. 9 and accordingly the corresponding wind fields also might vary as time elapses. In this respect, the swell arriving at a certain observation point is more likely to be a combination of some waves generated under different spatiotemporal source regions. Despite this restriction in the use of the method of Earle et al. (1984), the estimation result of wave source region for the second increase in wave height in February 2008 somehow matched well with the meteorological evidences showing formation of strong wind fields over the estimated source region. In order to obtain a more reliable estimation result, however, it is necessary to conduct numerical simulations using available wave models to track back the course of wave propagation from the source region and to directly relate the meteorological condition to the wave fields observed on the coast.

\section{Summary and conclusions}

In recent years, the occurrence of high waves in the winter season became common on the east coast of the Korean Peninsula. Public concerns are growing as the high waves have caused human casualties, damage to ships and coastal structures, and serious beach erosion along the coastline. In this paper, records of the high waves that occurred on the first day of 2011 were presented, with supplementary data of two other previous big wave events in October 2006 and February 2008. The "new year" wave of 1 January 2011 was monitored at nine measuring stations simultaneously along the east coast. By analyzing these wave data with the corresponding meteorological data, major characteristics of these waves were clarified in some detail.

The cause for the occurrence of high waves was found to be the long-lasting strong wind fields heading toward the east coast of Korea, which was formed as a result of the low pressure trough in the vicinity of the extra-tropical low pressure system that advances to the East Sea from China's inland 
with decreasing central pressure. Not only the pressure drop during the movement but also other factors in the meteorological conditions such as moving trajectory and staying time of the low pressure system together with arrangement of neighboring atmospheric pressure fields were found to have importance in determining characteristics of waves. The observed maximum significant wave heights exceeded $5 \mathrm{~m}$ as shown in the three wave records in October 2006, February 2008 , and January 2011, and the outbreak of such high waves is highly probable in the East Sea during every winter season. Therefore, it is necessary to be more prepared by enhancing predictability of the high waves, based on the understanding of the detailed mechanism of the rapid growth of the low pressure system, and by promptly developing an efficient operational wave prediction system.

Acknowledgements. This research was supported by a grant(12RTIP-B01) from Regional Technology Innovation Program by Ministry of Land, Infrastructure and Transport of Korean government and the research project (PE98943) of Korea Institute of Ocean Science and Technology. The authors are grateful to late Prof. Yoshimi Goda, professor Emeritus of Yokohama National University, who encouraged publishing this work when the earlier study was presented in the 2nd CDIT-KORDI Workshop held in Tokyo, Japan on 10 October 2010.

Edited by: E. Bitner-Gregersen

Reviewed by: three anonymous referees

\section{References}

Chung, H.-S.: Reviewing the explosively deepening cyclone (cyclonic bomb) over the East Sea with the satellite observations, J. Korean Soc. Remote Sens., 12, 126-138, 1996 (in Korean with English abstract).

Earle, M. D., Bush, K. A., and Hamilton, G. D.: High-height longperiod ocean waves generated by a severe storm in the northeast Pacific ocean during February 1983, J. Phys. Oceanogr., 14, 1286-1299, 1984.

Hasselmann, K.: On the non-linear energy transfer in a gravity-wave spectrum, Part 1. General theory, J. Fluid Mech., 12, 481-500, 1962.
Hasselmann, K., Munk, W., and MacDonald, G.: Bispectra of ocean waves, Proc. Symp. On Time Series Analysis, John Wiley, New York, 125-139, 1962.

Isozaki, I.: On the characteristics of coastal waves on the coast of Toyama bay (Report I), Notes of Cooperative Research for Disaster Prevention, 25, 3-15, 1971 (in Japanese with English abstract).

Isozaki, I. and Yoshio, O.: On the characteristics of coastal waves on the coast of Toyama bay (Report II), Notes of Cooperative Research for Disaster Prevention, 28, 3-17, 1972 (in Japanese with English abstract).

Jeong, W.-M., Oh, S.-H., and Lee, D. Y.: Abnormally high waves on the east coast, J. Korean Soc. Coast. Ocean Engrs., 19, 295-302, 2007 (in Korean with English abstract).

Jeong, W.-M., Oh, S.-H., Ryu, K.-H., Lee, D. Y., and Chae, J. W: Multi-station observation of the high swell along the east coast of Korea, Proc. 5th Int. Conf. Asian Pac. Coasts, Singapore, CDROM, 2009.

Kim, T. and Lee, K.: Hindcasting analysis of swells occurred in the east coast in February 2008, J. Korean Soc. Oceanogr., 15, 6267, 2010 .

Kitaide, M.: On the mechanism and forecasting of the so-called "Yorimawari" wave, Marine Report of the Central Meteorological Observatory, 2, 125-151, 1952 (in Japanese with English abstract).

Lee, H. S.: Abnormal storm waves in the East Sea (Japan Sea) in April 2012. Proc. 12th Int. Coast. Symp., (J. Coast. Res., Special Issue, 748-753,) 2013.

Lee, H. S., Kim, K. O., Yamashita, T., Komaguchi, T., and Mishima, T.: Abnormal storm waves in the winter East/Japan Sea: generation process and hindcasting using an atmosphere-wind wave modelling system, Nat. Hazards Earth Syst. Sci., 10, 773-792, doi:10.5194/nhess-10-773-2010, 2010.

Mase, H., Yasuda, T., Tom, T. H., Tsujio, D., and Mori, N.: Forecast and hindcast of waves which caused coastal disasters along Toyama Coasts on February 2009, Proc. 33rd IAHR Congress, 2854-2861, 2009.

Oh, S.-H., Jeong, W.-M., Lee, D. Y., and Kim, S. I.: Analysis of the reason for occurrence of large-height swell-like waves in the east coast of Korea, J. Korean Soc. Coast. Ocean Engrs., 22, 101-111, 2010 (in Korean with English abstract).

Suh, K. D., Oh, S. H., Hashimoto, N., and Ahn, K.: Laboratory observations of triad interaction of deep water wind waves, Coast. Eng. J., 42, 321-337, 2000.

Vanem, E., Natvig, B., and Huseby, A. B.: Modelling the effect of climate change on the wave climate of the World's oceans, Ocean Sci. J., 47, 123-145, 2012. 